\title{
Dispatching the problems in implementing mobile payment services from consumer attitude perspective
}

\author{
Hoang Thien Van¹, Vo Anh Tien², Huynh Cong Danh ${ }^{3}$, Hoang-Sy Nguyen ${ }^{4}$ \\ ${ }^{1,2}$ The Saigon International University (SIU), Ho Chi Minh City, Vietnam \\ ${ }^{3}$ Thu Dau Mot University, Thu Dau Mot City, Binh Duong Province, Vietnam \\ ${ }^{4}$ Faculty of Information Technology, Robotics and Artificial Intelligence, Binh Duong University, Thu Dau Mot City, \\ Binh Duong Province, Vietnam
}

\begin{tabular}{|c|c|}
\hline Article Info & ABSTRACT \\
\hline Article history: & Due to the abundance of internet and e-commerce (electronic commerce), an \\
\hline Received Oct 18, 2020 & $\begin{array}{l}\text { excessive amount of data has been generated causing an overload of } \\
\text { information to the current network infrastructure. As an attempt to solve this }\end{array}$ \\
\hline Revised Feb 24, 2021 & problem, there is a shift to mobile payment in the field of E-commerce. Thus, \\
\hline Accepted Mar 3, 2021 & $\begin{array}{l}\text { it is essential to study the adoption level of such service for global markets in } \\
\text { general and the Vietnamese market in specific. In this paper, we study the }\end{array}$ \\
\hline Keywords: & $\begin{array}{l}\text { consumers' attitude toward mobile payment, investigated with the theory of } \\
\text { planned behavior (TPB) from three perspectives, namely the consumer }\end{array}$ \\
\hline Consumer innovativeness & innovativeness, perceived benefit, and perceived risk. Accordingly, there are \\
\hline Electronic commerce & Thanks to the structural equation modeling (SEM) method, a population of \\
\hline Mobile payment & 250 Vietnamese mobile payment users was analyzed to confirm five out of the \\
\hline Perceived benefit & six hypotheses. It is drawn that the attitude toward the service is correlated \\
\hline Perceived risk & positively with the innovativeness and the perceived benefit, while being \\
\hline Theory of planned behavior & $\begin{array}{l}\text { correlated negatively with the perceived risk. Besides, the resulted model can } \\
\text { elucidate approximately } 49 \% \text { the consumers' intention to reuse the mobile } \\
\text { payment service. }\end{array}$ \\
\hline
\end{tabular}

This is an open access article under the CC BY-SA license.

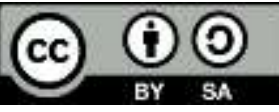

\section{Corresponding Author:}

Huynh Cong Danh,

Thu Dau Mot University,

Thu Dau Mot City, Binh Duong Province, Vietnam

Email: danhhc@tdmu.edu.vn

\section{INTRODUCTION}

Recently, the Vietnam e-commerce and information technology agency (VECITA) has been introduced as a flatform to announce the government policies supporting the growth of cross-border ecommerce. To accompany the development of the information and communication technologies (ICT), Vietnamese costumers have to have adequate adoption to mobile payment service. Nevertheless, according to [1], in the year of 2019 in Vietnam, only $17 \%$ of e-commerce websites was reported to provide online payment service (via website and mobile). Moreover, 37 over 67 banks provide mobile banking along with internet banking service. Additionally, from $45 \%$ of the population that uses internet, $62 \%$ involves in online transactions. Among those, no more than $20 \%$ uses online payment and $0.5 \%$ uses mobile banking services. Hence, studying the adoption level of Vietnamese consumers to mobile service can unlock the huge domestic market potential. In the existing literature, there are three primary factors employed to study the adoption level of consumers to new products or services, i.e. the consumer innovativeness, the perceived benefit, and the perceived risk. Those factors were considered separately [2-5], or together as in [6-11]. 
Based on either the perceived perspective or the consumer innovation, the adoption of information technology for innovation [2], the attitude toward using smartwatch and electronic products in general [3, 4], and the adoption to social commerce in small and medium-sized enterprises (SME) in Malaysia were studied. To analyze the interplay between factors, paper [6] empirically investigated the relation between the social factors and user behaviors on the largest social media flatform in China. In [7-9] considered the perceived benefit and perceived risk to study the customer adoption to the internet banking and ride-sharing service. Investigated as well the internet banking adoption; and study [9] that performance risk, financial risk and security risk are the most important factors to the mobile payment services, however, [10] replaced the perceived benefit with consumer innovativeness and evaluated it with the perceived risk. Moreover, [11] studied the mobile payment service adoption employing the trust factor alongside the two perceived perspectives.

The paper investigated solely the intention to reuse the service of individuals. Hence, future studies can be expanded to the actual service usage [12], the satisfaction after experiencing the services [13] of segmented individuals based on their demographic characteristics (different age groups and different monthly incoming). Besides, we can consider another factor namely the perceived value [14] and extend its relationship with the attitude and intention to use the service based on [15-16]. Finally, we can deploy random sampling to achieve better generalizability.

Inspired by those studies, based on the TPB, we utilized three factors including the perceived risk, consumer innovativeness, and perceived benefit to investigate their influence on the attitude toward mobile payment service. Moreover, from the obtained results, the consumers' reuse intention for the service was analyzed. The study was held in the Vietnam's largest e-commerce market, Ho Chi Minh City.

Aside from the Introduction, Section 2 introduces the research method including the theoretical review and research preparation. Section 3 reports the results and analysis. Finally, Section 4 discusses and concludes the findings from this paper.

\section{RESEARCH METHOD}

This paper begins with the theoretical review whereas six hypotheses were proposed. Then, in the subsection about the research preparation, we present the methodology to form the measurement model and structural model.

\subsection{Theoretical review}

a) Theory of planned behavior

The theory of planned behavior (TPB) has been developed and deployed in several domains, such as healthcare, marketing, management and public relation [17-19]. The theory investigates three factors that influence the self-conscious behaviors of an individual, which are the attitude, subjective norm, and perceived behavior control [20-24]. Concerning our study, the attitude of consumers towards mobile payment plays an essential role in predicting whether they will use this service. As for the subjective norm, the higher number of surrounding people who use the mobile payment, the more likely the individual will use the service. Lastly, the perceived behavior control is the judgement on the technical means, supporting infrastructure, financial barrier, and security. of the mobile payment made by the individual before using the service. Thus, to predict the behavioral intention of the people in Ho Chi Minh City towards the mobile payment services, we approach them with three initial hypotheses as follows:

- H1: There is a positive correlation between the attitude towards mobile payment services and the intention to reuse them.

- H2: There is a positive correlation between the subjective norm and the intention to reuse mobile payment services.

- H3: There is a positive correlation between the perceived control behavior and the intention to reuse mobile payment services.

b) Perceived risk

According to [2], consumers perceive several risks from mobile payment service are the financial risk, performance risk, time risk, social risk, security risk, psychological risk. Generally, if the perceived risk is obvious, consumers are less likely to perceive positive feelings in online payment, leading to less engagement in such activities [23]. We employ the performance, financial, security, time, and social risks in our definition of the perceived risk. Thereby, the fourth hypothesis is proposed as follows:

- H4: There is a positive correlation between the perceived risk and the intention to use mobile payment services. 
c) Consumer innovativeness

As in [23-24], there are two types of consumer innovativeness which are the hedonist innovativeness: the tendency to seek for the diversity via enjoying and changing to new products/services; and the social innovativeness: the tendency to rapidly familiarize with new technology to be prioritized over others. For our study, the consumer innovativeness is considered as a second-order construct with the hedonist and social innovativeness, since they both play a vital role in studying the innovation adopting level. Accordingly, the fifth hypothesis is proposed as follows:

- H5: There is a positive correlation between the consumer innovativeness and the attitude towards mobile payment services.

d) Perceived benefit

With regard to [7], we define the perceived benefit as the standard benefits that the consumers receive, which is directly proportional to the positive awareness of the consumers toward online transactions [22, 2529]. Thereby, we propose the final hypothesis relating to the perceived benefit as follows:

- H6: There is a positive correlation between the perceived benefit and the attitude towards mobile payment services.

\subsection{Research preparation}

We validated the TPB-based model from [30] utilizing the quantitative method with two incremental phases namely preliminary and official phases [31]. Specifically, samples were calibrated in the preliminary phase. It was then fed forward to the official phase, where quantitative evaluation was performed to validate the scaling of the model. The model scaling was constructed of the attitude, subjective norm, perceived behavior control, perceived benefit, intention to reuse, perceived risk, and consumer innovativeness. It should be noted that we used the 5-level Likert scale (from 1 to 5) to measure the consumers' attitude with 1 and 5 represent the strong disagreement and strong agreement.

The preliminary phase was realized with group discussions [32], which was divided into two rounds. In the first round, there were three people involved including a professor specialized in e-commerce and two experts from entities providing the payment services. The outcome of this first round was to specify the scaling for the research. Subsequently, in the second round, discussions were held in groups between four regular users invited by online payment service providers in Ho Chi Minh City, Vietnam. Regular users were chosen to answer closed questions to make sure that the survey samples were comprehensible and applicable for scaling and model validation.

Mobile payment services can be done online/remotely via websites or mobile applications, or in-store proximity mobile payment at the point-of-sale (POS) [25]. It should be noted that the contactless paying method is not popular in Ho Chi Minh City, thus, focus was paid solely on the online transaction sector.

\section{RESULTS AND ANALYSIS}

AMOS 20 software was deployed for model evaluation. According to [33, 34], we applied the twostep SEM method to assess at first the measurement model then the structural model. In particular, we evaluated the scales following Cronbach's Alpha reliability assessment and exploratory factor analysis (EFA). Subsequently, the composite reliability, the convergent and discriminant validities, and the overall suitability of the scales were assessed with confirmatory factor analysis (CFA). Eventually, utilizing the SEM technique with maximum likelihood estimation, the structural model was analyzed to confirm the overall suitability of the research model and validate the aforementioned hypotheses.

\subsection{Descriptive statistics}

The convenience sampling based on the six hypotheses was designed and conducted over two platforms being the paper surveys held over face-to-face interviews, and Google Form surveys distributed on social media. Since Facebook is the most popular social network in Vietnam according to VECITA in 2019 [1], we distributed the online survey on Facebook fan pages of the under-studied entities. We referred to [3335 ] for the list of online payment service providers including 13 fintech companies, 6 commercial and service companies providing as well the mobile payment service, and 6 traditional banks.

The first and foremost criterion to classify the responders is that they must be experienced using a smartphone or a tablet to perform any of the payment types including payment transfer, online payment on shopping websites, prepaid card payment, bill payment, online top-up payment. The responders having experience using several payment methods were asked to choose the most recent method to report to the survey. The survey attracted 400 responses within three months, and 250 of them were selected based on the aforementioned criteria for further evaluation. 
Table 1. Results of the measurement model

\begin{tabular}{lc}
\hline The Convergence Value Of The Scale & $\begin{array}{c}\text { Loading } \\
\text { Factor }\end{array}$ \\
\hline Security Risk (SR) (AVE=0.777; CR=0.874 ) & Deleted \\
I do not feel safe providing my personal information over the mobile payment services. (SRI) & 0.920 \\
I am worried using mobile payment services because other people may be able to access my account. & \\
(SR2) & 0.841
\end{tabular}

Financial Risk (FR) (AVE=0.665; $\mathrm{CR}=0.797$ )

When transferring money via mobile payment services, I am afraid of money loss due to careless mistakes such as filling wrong account number or wrong amount of money. (FR1)

When transaction errors occur, I do not get any compensation from the banks. (FR2)

I think using mobile payment services is a waste of money. (FR3)

I am worried that these services are not worth the money spent. (FR4)

I think it is not wise to pay fees for using mobile payment services. (FR5)

\section{Performance Risk (PR) (AVE=0.541; CR=0.701)}

Server for mobile payment service may not perform well due to slow speed or not updated website. (PR1) Server for mobile payment service may not proceed the payments correctly. (PR2)

I am doubted about the quality of mobile payment services. (PR3)

I am afraid that the functions of mobile payment services are not sufficient. (PR4)

I think mobile payment services do not bring good results. (PR5)

\section{Time Risk (TR) $(\mathrm{AVE}=0.575 ; \mathrm{CR}=0.724)$}

Using mobile payment services is inconvenient because I would spend lots of time fixing payment errors. (TR1)

It would take lots of time to learn how to use mobile payment services. (TR2)

I am afraid that using mobile payment services would waste my time since I need to change to using services at another bank. (TR3)

\section{Social Risk (SR) $(\mathrm{AVE}=\mathbf{0 . 8 6 3} ; \mathrm{CR}=\mathbf{0 . 9 2 6})$}

When I decide to use mobile payment services and something goes wrong with transactions, my friends would think less of me. (SR1)

When my bank account is invaded by hackers, I can potentially lose the status in my social relationships. (SR2)

If I use mobile payment services, surrounding people would not respect me anymore. (SR3)

Using mobile payment services may negatively affect my personal image in the eyes of others. (SR4)

When using mobile payment services, others will not see me as I want them to. (SR5)

I am afraid that others would look down on me when I use mobile payment services. (SR6)

Hedonist Innovativeness (IN) (AVE=0.743; CR=0.852 )

I like buying new products than known products/services. (IN1)

I like buying new and original products/services. (IN2)

New products/services always excite me. (IN3)

\section{Social Innovativeness $(\mathrm{IS})(\mathrm{AVE}=\mathbf{0 . 7 2 0} ; \mathrm{CR}=\mathbf{0 . 8 3 7})$}

I am usually the first among my friends to try out new products/services. (IS1)

I know more than others on latest products/services. (IS2)

I try new products/services before my neighbors. (IS3)

\section{Perceived Benefit (PB) (AVE=0.636; CR=0.777)}

I think using mobile payment services can save the transaction handling fees related to banking transactions. (PB1)

Using mobile payment services can bring me more product/service choices and other opportunities. (PB2)

I think using mobile payment services can save time. (PB3)

\section{Subjective Norm $(\mathrm{SN})(\mathrm{AVE}=\mathbf{0 . 7 0 3} ; \mathrm{CR}=\mathbf{0 . 8 2 6})$}

My relatives think that I should use mobile payment services. (SN1)

My friends recommend me to use mobile payment services. (SN2)

I use the mobile payment services due to influence from the media. (SN3)

Perceived Behavior Control (PC) $(\mathrm{AVE}=0.603 ; \mathrm{CR}=0.752)$

I can use the mobile payment services well. (PC1)

I think that using mobile payment services is entirely within my control. (PC2)

I have enough resources to use mobile payment services. (PC3)

I have knowledge to use mobile payment services. (PC4)

I have the skill to use mobile payment services. (PC5)

$$
\text { Attitude (AT) }(\mathrm{AVE}=\mathbf{0 . 6 0 5} ; \mathrm{CR}=\mathbf{0 . 7 5 3})
$$

I think using mobile payment services is a good idea. (AT1)

I think using mobile payment services for financial transactions would be a wise idea. (AT2)

Using mobile payment services is pleasant. (AT3)

Using mobile payment services is highly desirable. (AT4)

Intention to Reuse $(\mathrm{IT})(\mathrm{AVE}=\mathbf{0 . 5 8 2} ; \mathrm{CR}=\mathbf{0 . 8 0 5})$

I would use mobile payment services for my banking needs. (IT1)

I would definitely use mobile payment services for banking transactions. (IT2)

Deleted

Deleted

0.737

0.887

Deleted

Deleted

Deleted

0.682

Deleted

0.786

Deleted

0.615

0.878

Deleted

Deleted

0.880

0.975

Deleted

Deleted

Deleted

0.907

0.814

Deleted

0.867

0.830

Deleted

0.838

0.755

0.804

0.872

Deleted

Deleted

Deleted

0.753

Deleted

0.799

0.831

0.721

Deleted

Deleted

0.800

0.840

In the upcoming time, I would utilize online payment services in replacement for traditional payment 0.633 services. (IT3) 
From descriptive statistics point of view, we obtained the following information from the responders: gender: $53.2 \%$ male and $46.8 \%$ female; age: $50.8 \%$ from 18 to $30,33.6 \%$ from 31 to $45,15.6 \%$ under 18 or over 35; educational background: $44.8 \%$ university, $36.4 \%$ college, $18.8 \%$ other; monthly income: $43.6 \%$ makes 4-8 million VND, 28.8\% makes 8-12 million VND, 19.2\% less than 4 million VND, 19.2\% more than 12 million VND; marriage status: $62.4 \%$ married, $37.6 \%$ single.

\subsection{Measurement model}

The answers to the survey questions were evaluated in Table 1 with regard to [34]. The Cronbach's Alpha assessment result indicates that the scales meet our desired confidence level (alpha >0.7). Besides, the EFA shows that the structural factor of the model is appropriate with loading factors $>0.5$. Then, we apply the CFA assessment and remove some observed variables which bring in a high correlation between measurement errors, given that the removal does not affect the content validity of the scales. Besides, the convergent validity of the scales is satisfactory with the composite reliability (CR) from 0.701 to $0.926(>0.7)$, and the average variance extracted (AVE) from 0.541 to $0.863(>0.5)$.

As for Table 2, since the AVE is larger than the correlation coefficients of the respective pair, the discriminant validity of the scale meets the requirement. Subsequently, the proposed measurement model is suitable for the collected data in [34], with the suitability indexes of: CMIN/df=1.785 $(<3), \mathrm{p}=0.000(<0.05)$, RMSEA=0.056 (<0.08), AGFI=0.844 (>0.08), TLI=0.918 (>0.9) and CFI=0.944 (>0.9).

Table 2. Discriminant validity assessment results

\begin{tabular}{|c|c|c|c|c|c|c|c|c|c|c|c|c|}
\hline Construct & IT & SR & FR & PR & TR & OR & IN & IS & PB & $\mathbf{A T}$ & SN & PC \\
\hline FR & 0.003 & 0.155 & 0.665 & & & & & & & & & \\
\hline TR & 0.002 & 0.042 & 0.167 & 0.288 & 0.575 & & & & & & & \\
\hline OR & 0.031 & 0.042 & 0.116 & 0.139 & 0.132 & 0.863 & & & & & & \\
\hline IN & 0.006 & 0.096 & 0.040 & 0.038 & 0.020 & 0.149 & 0.743 & & & & & \\
\hline AT & 0.364 & 0.016 & 0.013 & 0.011 & 0.000 & 0.000 & 0.088 & 0.199 & 0.170 & 0.605 & & \\
\hline SN & 0.146 & 0.007 & 0.006 & 0.032 & 0.010 & 0.003 & 0.017 & 0.170 & 0.382 & 0.127 & 0.703 & \\
\hline PC & 0.116 & 0.025 & 0.000 & 0.044 & 0.000 & 0.002 & 0.000 & 0.016 & 0.157 & 0.203 & 0.141 & 0.603 \\
\hline
\end{tabular}

\subsection{Structural Model}

Table 3 shows that five out of the six proposed hypotheses are accepted. Since the impact of perceived behavior control to the intention to reuse is not statistically significant, (P-value $>0.05$ ), H3 is rejected. From the SEM assessment, we can see that the suitability indexes of the theoretical model satisfy [33]: Chisquared/df=1.944 (<3), p=0.000 (<0.005), RMSEA=0.062 (<0.08), AGFI=0.839 (>0.8), TLI=0.902 (>0.9) and $\mathrm{CFI}=0.919(>0.9)$.

Table 3. Summary of hypothesis tests

\begin{tabular}{clcc}
\hline \multicolumn{1}{c}{ Hypotheses } & Standardized coefficient & P-value & Result \\
\hline H6 & Perceived Benefit $\rightarrow$ Attitude & 0.283 & Accepted \\
H5 & Cosumer Innovativeness $\rightarrow$ Attitude & 0.560 & Accepted \\
H4 & Perceived Risk $\rightarrow$ Attitude & -0.297 & 0.002 \\
H3 & Perceived Behavior Control $\rightarrow$ Intention to & - & 0.398 \\
& Reuse & & Rejected \\
H2 & Subjective Norm $\rightarrow$ Intention to Reuse & 0.350 & 0.001 \\
H1 & Attitude $\rightarrow$ Intention to Reuse & 0.515 & Accepted \\
Notes: $* * *$ p-values $<0.001$ & & Accepted \\
\hline
\end{tabular}

Readers can refer to Figure 1 for the results of the analysis. 


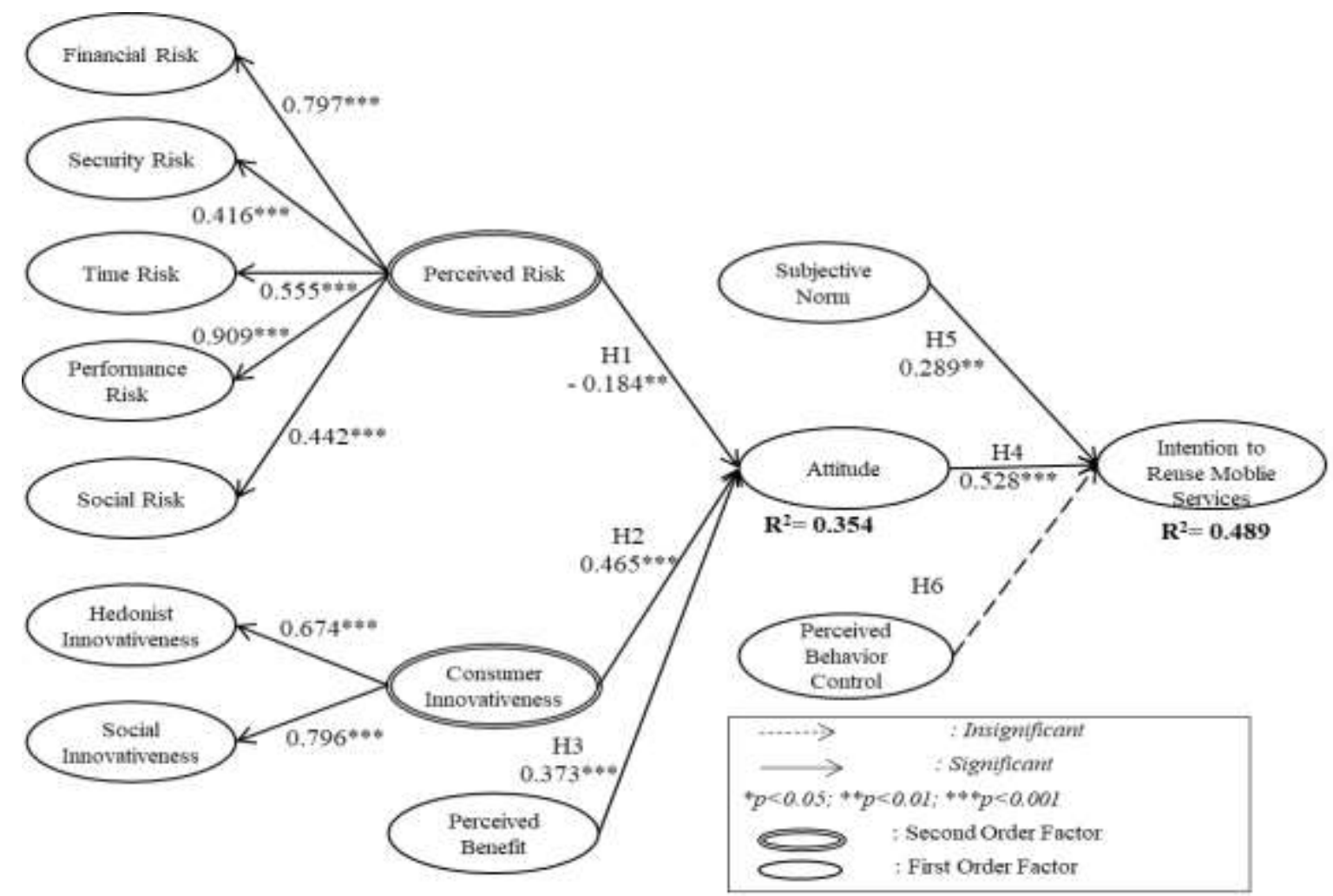

Figure 1. Structural model showing results of analysis

\section{RESULTS AND DISCUSSION}

Thanks to the model established from TPB, the three factors i.e. the consumer innovativeness, perceived benefit, and perceived risk are proven to be positively correlated with the attitude towards mobile payment services with values of $0.56,0.30$, and 0.28 . Besides, the proposed theoretical model shows that five out of the six hypotheses are accepted which can explain up to $49 \%$ the intention to reuse mobile payment services in Ho Chi Minh City, Vietnam. Moreover, aside from finding out that the consumer innovativeness has a theoretically significant impact on the behavioral intention, it was statistically shown that this factor can be constructed as a second-order instead of two distinct first-orders, i.e. hedonist and social innovativeness as in [4].

\section{CONCLUSION}

There are a number of managerial implications that can be made based on the accepted hypotheses in this paper. In particular, with regard to hypothesis $(H 1)$, service providers can promote more appropriate campaigns targeting different customer segments. Based on hypothesis (H5), on one hand, the advertising content can be created focusing on the innovation perspective to promote the benefits of the state-of-the-art technologies or new service experiences (hedonist innovativeness). On the other hand, advertisements can feature the consumers' personal images or positions upon using the services (social innovativeness). Besides, as proven in hypothesis $(\mathrm{H} 2)$, service providers can extend their promotion range to communities or groups instead of focusing solely on individuals. Furthermore, aside from promoting the potential benefits of services, investments need to be paid to diminish possible risks to the customers, hypothesis (H4) and hypothesis (H6). In particular, service providers should continuously improve the security standard regarding handling the personal information and online payment services (security risk factor), update the technology and supporting infrastructure (performance risk factor), and refine the service guarantee policies (financial risk).

\section{ACKNOWLEDGEMENTS}

Thanks for the Saigon International University (SIU) funds supporting this project. This research is as well funded by Thu Dau Mot University under grant number DT.20.2-019. 


\section{REFERENCES}

[1] Vietnam E-commerce association (VECOM), "E-Business Index 2019," 2020. Website: http://en.vecom.vn/document/17185

[2] J. D. Wells, D. E. Campbell, J. S. Valacich, and M. Featherman," The effect of perceived novelty on the adoption of information technology innovations: a risk/reward perspective," Decision Sciences, vol. 41,no. 4, pp. 813-843, 2010, doi: 10.1111/j.1540-5915.2010.00292.x.

[3] J. Hong, P. Lin, and P. Hsieh, "The effect of consumer innovativeness on perceived value and continuance intention to use smartwatch," Computers in Human Behavior, vol. 67, pp. 264-272, 2017, doi: 10.1016/j.chb.2016.11.001.

[4] S. Heidenreich, and T. Kraemer, "Passive innovation resistance: The curse of innovation? Investigating consequences for innovative consumer behavior," Journal of Economic Psychology, vol. 51, pp. 134-151, 2015, doi: 10.1016/j.joep.2015.09.003.

[5] W. A. Ali, M. Mukhtar, and I. Mohamed, "Validating the factors influencing social commerce adoption in small and medium enterprise in Malaysia", Indonesian Journal of Electrical Engineering and Computer Science, vol. 17, no. 1, pp. 440-447, 2020, doi: 10.11591/ijeecs.v17.i1.pp440-447.

[6] Y. Bai, Z. Yao, and Y.-F. Dou, "Effect of social commerce factors on user purchase behavior: An empirical investigation from renren.com," International Journal of Information Management, vol. 35, no. 5, pp. 538-550, 2015, doi: 10.1016/j.ijinfomgt.2015.04.011.

[7] M.-C. Lee, "Factors influencing the adoption of internet banking: An integration of TAM and TPB with perceived risk and perceived benefit," Electronic commerce research and applications, vol. 8, no. 3, pp.130-141, 2009, doi: 10.1016/j.elerap.2008.11.006.

[8] Y. Wang, J. Gu, S. Wang, and J. Wang, "Understanding consumers' willingness to use ride-sharing services: The roles of perceived value and perceived risk," Transportation Research Part C: Emerging Technologies, vol.105, pp.504-519, 2019, doi: 10.1016/j.trc.2019.05.044.

[9] L.-A. Casado-Aranda, J. Sánchez-Fernández, and F. J. Montoro-Ríos, "How consumers process online privacy, financial, and performance risks: An fMRI Study," Cyberpsychology, Behavior, and Social Networking, vol. 21, no. 9, pp. 556-562, 2018.

[10] V. Chauhan, R. Yadav, and V. Choudhary, "Analyzing the impact of consumer innovativeness and perceived risk in internet banking adoption," International Journal of Bank Marketing, vol.37, no.1, pp.323-339, 2019, doi: 10.1108/IJBM-02-2018-0028.

[11] E.L., Slade, Y.K., Dwivedi, N.C., Piercy, M.D., Williams, "Modeling Consumers' Adoption Intentions of Remote Mobile Payments in the United Kingdom: Extending UTAUT with Innovativeness, Risk, and Trust", Psychology \& Marketing, vol. 32, pp. 860-873, 2015.

[12] J. Park, E. Amendah, Y. Lee. and H. Hyun, "M-payment service: Interplay of perceived risk, benefit, and trust in service adoption," Human Factors and Ergonomics in Manufacturing \& Service Industries, vol.29, no. 1, pp.31-43, 2018, doi: 10.1002/hfm.20750.

[13] E. Kardes, F. Ord'õnez, and R. W. Hall, "Discounted robust stochastic games and an application to queueing control," Operations research, vol. 59, no. 2, pp. 365-382, 2011.

[14] M. G. Gallarza, I. Gil-Saura, and M. B. Holbrook, "The value of value: Further excursions on the meaning and role of customer value, " Journal of consumer behaviour, vol. 10, no. 4, pp. 179-191, 2011.

[15] R. Salehzadeh, and J. K. Pool, "Brand attitude and perceived value and purchase intention toward global luxury brands," Journal of International Consumer Marketing, vol. 29, no. 2, pp. 74-82, 2017

[16] M. Hubert, M. Blut, C. Brock, C. Backhaus, and T. Eberhardt, "Acceptance of smartphone-based mobile shopping: Mobile benefits, customer characteristics, perceived risks, and the impact of application context," Psychology \& Marketing, vol. 34, no. 2, pp. 175-194, 2017.

[17] I. Ajzen, "From intentions to actions: A theory of planned behavior," Action control, pp.11-39, 1985.

[18] I. Ajzen, "The theory of planned behaviour: Reactions and reflections", Psychology \& Health, vol.26, no.9, pp.11131127, 2011.

[19] F. A. Athab, and W. S.Majeed, "Economic power dispatch for an interconnected power system based on reliability indices", Indonesian Journal of Electrical Engineering and Computer Science, vol.20, no.2, pp. 777-787, 2020.

[20] I. Ajzen, "The theory of planned behavior," Organizational behavior and human decision processes, vol.50, no. 2, pp.179-211, 1991.

[21] I. Ajzen, "Perceived behavioral control, self-efficacy, locus of control, and the theory of planned behavior," Journal of applied social psychology, vol. 32, no. 4, pp.665-683, 2002.

[22] B. Hern' andez, J. Jim' enez, and M. J. Mart' in, "Customer behavior in electronic commerce: The moderating effect of e-purchasing experience," Journal of business research, vol. 63, no. 9-10, pp. 964-971, 2010

[23] T. Kuisma, T. Laukkanen, and M. Hiltunen, ” Mapping the reasons for resistance to Internet banking: Ameans-end approach," International Journal of Information Management, vol. 27, no. 2, pp. 75-85, 2007

[24] M. Y. Yi, K. D. Fiedler, and J. S. Park, "Understanding the role of individual innovativeness in the acceptance of ITbased innovations: Comparative analyses of models and measures," Decision Sciences, vol. 37, no. 3, pp. 393-426, 2006.

[25] G. Roehrich, "Consumer innovativeness: Concepts and measurements," Journal of business research, vol.57, no. 6, pp. 671-677, 2004.

[26] S. A Orange, et al.," Mobile Payment Market - Global Opportunity Analysis and Industry Forecast, 2016-2023," Retrieved from Allied Market Research, 2018. Website: 
https://www.reportbuyer.com/product/5273176/mobile-payment-market-global-opportunity-analysis-and-industryforecast-2016-2023.html,

[27] S. Forsythe, C. Liu, D. Shannon, and L. C. Gardner, "Development of a scale to measure the perceived benefits and risks of online shopping," Journal of interactive marketing, vol. 20, no. 2, pp. 55-75, 2006.

[28] K. C. Gehrt, and S. Shim, "A shopping orientation segmentation of French consumers: Implications forcatalog marketing," Journal of interactive Marketing, vol. 12, no. 4, pp.34-46, 1998.

[29] I.-H. Hung, and S.-W. Chou, "Understanding the formation of e-loyalty based on a dedication-constraint perspective," Journal of Organizational Computing and Electronic Commerce, vol. 27, no. 1, pp. 48-65, 2017.

[30] D. Straub, "Validating Instruments in MIS Research," MIS Quarterly, vol. 13, no. 2, pp. 147-169, 2008.

[31] J. F. Hair, C. M. Ringle, and M. Sarstedt, "PLS-SEM: Indeed a silver bullet," Journal of Marketing theoryand Practice, vol. 19, no. 2, pp. 139-152, 2011.

[32] D. Straub, M.-C. Boudreau, and D. Gefen, "Validation guidelines for IS positivist research," Communications of the Association for Information systems, vol. 13, no. 1, pp. 24, 2004.

[33] Mobilepaymentsremittance, "Southeast Asia Becomes Centre for In-stant Cross-Border Payments Growth," Fintech news Singapore, 2020. Website: https://fintechnews.sg/43966/mobilepayments/southeast-asia-becomes-center-ofinstant-cross-border-payments-growth/

[34] J. F. Hair, R. E. Anderson, R. L. Tatham, and W. C. Black, "Multivariate data analysis (4th ed.): with readings", Prentice-Hall, Inc., USA., 1998.

[35] K. Rouibah, P. B. Lowry, and Y. Hwang, "The effects of perceived enjoyment and perceived risks ontrust formation and intentions to use online payment systems: New perspectives from an Arab country," Electronic Commerce Research and Applications, vol. 19, pp. 33-43, 2016. 